\title{
Medication errors as malpractice-a qualitative content analysis of 585 medication errors by nurses in Sweden
}

\author{
Karin Sparring Björkstén ${ }^{1,4^{*}}$, Monica Bergqvist ${ }^{1}$, Eva Andersén-Karlsson ${ }^{2,3}$, Lina Benson ${ }^{2,3}$ and Johanna Ulfvarson ${ }^{1}$
}

\begin{abstract}
Background: Many studies address the prevalence of medication errors but few address medication errors serious enough to be regarded as malpractice. Other studies have analyzed the individual and system contributory factor leading to a medication error. Nurses have a key role in medication administration, and there are contradictory reports on the nurses' work experience in relation to the risk and type for medication errors.

Methods: All medication errors where a nurse was held responsible for malpractice $(n=585)$ during 11 years in Sweden were included. A qualitative content analysis and classification according to the type and the individual and system contributory factors was made. In order to test for possible differences between nurses' work experience and associations within and between the errors and contributory factors, Fisher's exact test was used, and Cohen's kappa ( $k$ ) was performed to estimate the magnitude and direction of the associations.

Results: There were a total of 613 medication errors in the 585 cases, the most common being "Wrong dose" (41\%), "Wrong patient" (13\%) and "Omission of drug" (12\%). In $95 \%$ of the cases, an average of 1.4 individual contributory factors was found; the most common being "Negligence, forgetfulness or lack of attentiveness" (68 \%), "Proper protocol not followed" (25 \%), "Lack of knowledge" (13\%) and "Practice beyond scope" (12\%). In 78 \% of the cases, an average of 1.7 system contributory factors was found; the most common being "Role overload" (36 \%), "Unclear communication or orders" (30\%) and "Lack of adequate access to guidelines or unclear organisational routines" (30\%). The errors "Wrong patient due to mix-up of patients" and "Wrong route" and the contributory factors "Lack of knowledge" and "Negligence, forgetfulness or lack of attentiveness" were more common in less experienced nurses. The experienced nurses were more prone to "Practice beyond scope of practice" and to make errors in spite of "Lack of adequate access to guidelines or unclear organisational routines".
\end{abstract}

Conclusions: Medication errors regarded as malpractice in Sweden were of the same character as medication errors worldwide. A complex interplay between individual and system factors often contributed to the errors.

Keywords: Medication error, Classification, Contributory factor, Nurse, Malpractice

Abbreviation: ICF, Individual contributory factor; IMSN, International medication safety network; IVO, Health and social care inspectorate; ME, Medication error; NBHW, National board of health and welfare (in Sweden); RN, Registered nurse; SCF, System contributory factor

\footnotetext{
* Correspondence: Karin.Sparring.Bjorksten@ki.se

${ }^{1}$ Department of Neurobiology, Care Sciences and Society, Karolinska Institutet, Stockholm, Sweden

${ }^{4}$ Psychiatry South Stockhholm, Administration och Ledning, Box 5040SE-121

05 Johanneshov, Sweden

Full list of author information is available at the end of the article
} 


\section{Background}

Medication errors (MEs) are probably the most common type of patient safety incidents worldwide and cause harm to patients, distress to medical staff and costs to the health care system. Systematic reporting of errors is fundamental for detecting patient safety problems, but there is no consensus neither concerning the terminology of MEs nor the error reporting systems. A few countries have developed advanced national incident reporting systems but a variety of local reporting systems are used elsewhere [1]. The International Medication Safety Network (IMSN) aims to develop a common and systematic terminology as a basis for powerful prevention strategies [2].

The five most common methods for detecting MEs are: 1) studies of errors reported to the authorities, 2) studies of errors reported spontaneously to local reporting systems, 3) screening of medication orders and patient medical charts, 4) observational studies, and 5) qualitative studies in which healthcare personnel are interviewed.

Probably, only about $5 \%$ of MEs are reported $[3,4]$. The traditional roles of reporting systems are punitive. Health care professionals may be criticized or even lose their licence. Reporting an error is often regarded as a way to blame and shame, although MEs often arise due to the complex interplay between circumstances in a busy clinical setting [5]. A non-punitive ME reporting system, however, can be used to learn from errors, provide feedback to those involved and improve routines.

The lack of a generally accepted terminology makes comparisons difficult. A recent meta-analysis from the United Kingdom revealed three different definitions of medication administration errors, 44 sub-categories and four denominators [6]. Some researchers have suggested how to analyse and classify the underlying reasons that lead to MEs as reviewed by Brady et al. [7]. Insignificant MEs are more common than hazardous MEs and may or may not have different reasons and underlying mechanisms $[8,9]$.

Registered nurses (RNs) are responsible for medication administration in most setting and are therefore the health professionals most often reported for MEs [10]. Depending on workplace, RNs spend up to $40 \%$ of working hours administering and managing drugs [11], and are the gate-keepers for intercepting MEs and mitigating its consequences [12].

The clinical experience of the nurse is important to what kind of unsafe actions the nurse may take before an error occurs [13]. Clinically inexperienced nurses may be more affected by system factors than experienced nurses. Studies linking nurses' clinical experince and MEs are, however, inconclusive. Some studies have shown correlations between inexperienced nurses and an increased risk for MEs [14-18], whereas others did not find such correlations $[19,20]$.
At the time of the study, all Swedish healthcare providers were required to report potentially dangerous treatment-related adverse events to the National Board of Health and Welfare (NBHW). The NBHW could criticize individual health care professionals as well as the routines in the health-care unit. The crucial point was not the actual harm to the patient but the potential risk of an event. In rare cases, the NBHW could report individuals to a criminal court, but Sweden does not have a tradition of taking medical issues to court. The system has gradually been replaced by local reporting systems intended to detect system errors rather than criticizing individuals, but the most serious cases must today be reported to a new authority, the Health and Social Care Inspectorate (IVO).

There are many studies that survey the number and the type of reported MEs in different settings, but few in-depth studies focussing on hazardous MEs made by nurses. In order to get a deeper understanding of the process leading a hazardous ME, we conducted a twophase study of ME by nurses serious enough to be judged as malpractice in Sweden. The first phase served to develop a classification system for MEs and system and individual contributory factors based on 33 medication errors [5]. The present paper reports the second phase where all MEs during 11 years where a nurse was found responsible by the NBHW were analyzed using the above classification system.

The aim of this work was to increase the understanding of potentially hazardous MEs by nurses with regard to the type of error, the individual contributory factors and the work experience of the nurse and the system contributory factors of the workplace.

\section{Methods}

Cases were selected from the NBHW reports of potentially hazardous reported MEs in Sweden. All reported MEs from Jan 1, 1996 to Dec 31, 2006 where a nurse was held responsible for malpractice were selected $(n=585)$. The case files included the original report about the error, the patient records, event descriptions from the nurse and other medical staff involved and sometimes from the patients and finally the assessment and conclusions by the NBHW. Some case files were short and uncomplicated whereas others were extensive. The complete case files were photo-copied and formed the base for the study, and were then systematically scrutinized.

The 585 MEs were made in a variety of health care settings; 243 cases (42\%) in hospital based care, 221 cases (38 \%) in nursing homes, 63 cases (11\%) in home care services and 44 cases $(8 \%)$ in outpatient care. Health care setting was missing in 14 (2\%) cases.

The patients were aged 2 months -98 years of age. There were 43 children $<18$ years of age ( $7 \%), 156$ patients aged $18-65$ years of age $(27 \%)$ and 354 patients $>65$ years of 
age (60\%). Patient age was missing in 32 cases (6\%). There were 310 female (53\%) and 248 male (42\%) patients. Patient gender was missing in 32 cases (6\%).

All the nurses were registered nurses (RNs). Sweden does not have a system for grading nurses. Mean age was 44 (Range 24-64) years of age. There were 444 women (76\%) and 79 men (13\%). Gender was missing in 62 cases (11\%). There were 317 nurses with $>2$ years of work experience $(54 \%)$ and 55 nurses with $<2$ years of work experience ( $9 \%)$. Work experience was missing in 213 of the cases (36\%). Mean work experience was 10 years.

A qualitative content analysis was conducted on the narratives in the 585 case files to classify the errors into different types and to identify the individual contributory factors (ICFs) and the system contributory factors (SCFs) that preceded the error using the analysis procedure described by Graneheim and Lundman [21].

Three RN researchers trained in qualitative methodology made the content analysis and classified the cases according to the type of ME and contributing factors using a modification of the classification described by Bergqvist et al. [5].

The analysis was made in four steps. Firstly, the case file was read several times to get an understanding of the whole. Secondly, the text was divided into meaning units. Thirdly, the meaning units were summarized (condensed) and labelled with codes. Finally, the codes were sorted into subcategories and main categories which were based on the comparison on the similarities and differences (Graneheim and Lundman, 2004). The four-step content analysis process is demonstrated in Table 1.

The MEs were assigned to nine categories as shown in Table 2: 1) wrong dose, 2) wrong drug due to mix-up of drugs, 3) wrong patient due to mix-up of patients, 4) Omission 5) unauthorized drug, 6) wrong route, 7) wrong judgement or inadequate assessment of the patient's need for treatment, 8) wrong management or storage of the drug, and 9) allergy-related error. The categories "Wrong patient", "Wrong judgement (or inadequate assessment of the patient's need for treatment)" and "Wrong management or storage of the drug" were, not present in the methodological study built on a smaller material $(n=33)$, but were developed for this study by the same researchers using the same method [5].

The ICFs were assigned to six categories as shown in Table 3: 1) negligence, forgetfulness or lack of attentiveness, 2) proper protocol not followed, 3) lack of knowledge, 4) practice beyond scope of practice, 5) inappropriate communication (including documentation errors), and 6) disease or drug abuse. The SCFs were assigned to eight categories as shown in Table 4: 1) role overload, 2) unclear communication or orders, 3) lack of adequate access to guidelines or unclear organisational routines, 4) inappropriate location of medication or look-alike medication, 5) interruption or distraction when preparing or administering medication, 6) inadequate technique or pharmaceutical service, 7) pressure from patient/patient's family or other staff members to satisfy the patient's immediate need, and 8) administration in an emergency situation. The categories" Inadequate technique or pharmaceutical service" and "Administration in an emergency situation" and "Unclear communication or orders" were not present in the methodological study but were developed for this study by the same researchers using the same method [5]. The categories "organizational routines" and "lack of adequate access to guidelines or information" were due to overlap treated as one category "Lack of adequate access to guidelines or unclear organizational routines".

Patient harm was classified as no harm, moderate harm, serious (permanent) harm, and death.

Table 1 The four-step content analysis process

\begin{tabular}{|c|c|c|c|c|}
\hline Meaning unit & Condensation & & Main category & Sub-category \\
\hline $\begin{array}{l}\text { Nurse finds an opened vial with sodium chloride } \\
\text { solution on the tray "as it usually is" and injects } 5 \mathrm{ml} \text {. } \\
\text { Later, two unopened vials of sodium chloride } \\
\text { solution and one opened vial of potassium } \\
\text { chloride solution are found on the tray. }\end{array}$ & $\begin{array}{l}\text { Nurse found an opened vial } \\
\text { of sodium chloride. "As it usually is." } \\
\text { "No thought that it could be } \\
\text { anything else" }\end{array}$ & $\begin{array}{l}\text { Potassium chloride } \\
\text { instead of sodium } \\
\text { chloride }\end{array}$ & $\begin{array}{l}\text { Medication } \\
\text { error type }\end{array}$ & $\begin{array}{l}\text { Wrong drug due } \\
\text { to mix-up of drugs }\end{array}$ \\
\hline $\begin{array}{l}\text { "I read on the vial, but I didn't notice what it said." } \\
\text { "She didn't notice of the small dose prescribed, } \\
\text { but took it for granted that the patient should } \\
\text { have an ordinary dose." } \\
\text { "I totally forgot about the medication." }\end{array}$ & $\begin{array}{l}\text { Did not pay attention to the } \\
\text { content of the text } \\
\text { Didn't notice and took for } \\
\text { granted } \\
\text { Forgot to give the medicine } \\
\text { to the patient }\end{array}$ & $\begin{array}{l}\text { Insufficient attention } \\
\text { Took for granted } \\
\text { Forgot }\end{array}$ & $\begin{array}{l}\text { Individual } \\
\text { factor }\end{array}$ & $\begin{array}{l}\text { Negligence, } \\
\text { forgetfulness } \\
\text { or lack of } \\
\text { attentiveness }\end{array}$ \\
\hline $\begin{array}{l}\text { "I was alone and the medication administration } \\
\text { must be done at all the wards at the same time" }\end{array}$ & $\begin{array}{l}\text { Alone with all administration } \\
\text { at the same time }\end{array}$ & $\begin{array}{l}\text { To much work to } \\
\text { perform in } \\
\text { insufficient time }\end{array}$ & System factor & Role overload \\
\hline
\end{tabular}


Table 2 The nine different categories of medication errors

\begin{tabular}{|c|c|c|}
\hline Error type & $N(\%)$ & Stories illustrating the categories \\
\hline Wrong dose & $241(41)$ & $\begin{array}{l}\text { Due to bad communication between } \\
\text { a nurse and an assistant nurse, they } \\
\text { both gave a woman with diabetes } \\
\text { insulin. }\end{array}$ \\
\hline Wrong drug & $96(16)$ & $\begin{array}{l}\text { A man with heart failure was given } \\
\text { morphine instead of furosemide } \\
\text { intravenously because the nurse } \\
\text { was thinking of another patient. }\end{array}$ \\
\hline Wrong patient & $76(13)$ & $\begin{array}{l}\text { An in-patient was given drugs that } \\
\text { were meant for the patient in the } \\
\text { next bed. }\end{array}$ \\
\hline Omission & $69(12)$ & $\begin{array}{l}\text { A patient did not get warfarin for } 2 \\
\text { weeks since the medication was } \\
\text { temporarily discontinued and then } \\
\text { forgotten. }\end{array}$ \\
\hline Unauthorized drug & $57(10)$ & $\begin{array}{l}\text { A nurse gave a patient with severe } \\
\text { pain a higher dose of analgesics } \\
\text { than prescribed because the lower } \\
\text { dose had not resulted in pain relief. } \\
\text { No physician was available at the time. }\end{array}$ \\
\hline Wrong route & $35(6)$ & $\begin{array}{l}\text { Due to a misunderstanding of the } \\
\text { nurse's instructions, an assistant nurse } \\
\text { administered ear drops into the eyes } \\
\text { of a nursing home patient. }\end{array}$ \\
\hline $\begin{array}{l}\text { Wrong judgement } \\
\text { (or inadequate } \\
\text { assessment of } \\
\text { the patient's need } \\
\text { for treatment) }\end{array}$ & $16(3)$ & $\begin{array}{l}\text { A patient who had very a low blood } \\
\text { sugar was nevertheless given her } \\
\text { prescribed dose of insulin. }\end{array}$ \\
\hline $\begin{array}{l}\text { Wrong management } \\
\text { or storage of the drug, }\end{array}$ & $11(2)$ & $\begin{array}{l}\text { A nurse who could not find the proper } \\
\text { drug picked up a package from a box } \\
\text { of discarded drugs and gave it to the } \\
\text { patient. }\end{array}$ \\
\hline Allergy-related error & $9(2)$ & $\begin{array}{l}\text { Using the department's the list of drugs } \\
\text { that nurses are allowed to administer } \\
\text { occasionally without a doctor's order, } \\
\text { a nurse administered alimemazine to } \\
\text { a patient from without noticing that } \\
\text { the patient was allergic to this drug. }\end{array}$ \\
\hline
\end{tabular}

Other $\quad 3(<1)$

Total numbers of 613 errors in the 585 cases

Table 2 shows the nine different categories of medication errors, the number and the percent calculated in relation to the 585 cases for each category and examples illustrating each category

\section{Statistics}

Number (n) and percent (\%) were reported for the ME types, ICFs, and SCFs for all cases and, in addition, also split by nurses' work experience. In order to test for possible differences between work experience and associations within and between the errors and contributory factors, Fisher's exact test was used, and Cohen's kappa (k) was performed to estimate the magnitude and direction of the associations. All analyses were performed in $\mathrm{R}$, version 3.1.3 (R Foundation for Statistical Computing, Vienna, Austria).

\section{Results}

The medication errors (MEs)

A total of 613 MEs were found in the 585 case files. The most common ME was "Wrong dose" in $41 \%$ of the cases. "Wrong dose" correlated negatively with "wrong drug" $(k=$ $-0.28, p<0.001)$, "wrong patient" $(k=-0.25, p<0.001)$ and "omission" $(k=-0.21, p<0.001)$. Other common MEs were "Wrong drug" (16 \%), "Wrong patient" (13 \%) and "Omission of drug" (12\%). In three cases, the information available was in-sufficient to determine the error type. Table 2 shows the frequency of the nine different error categories along with illustrating examples.

\section{The individual contributory factors (ICFs)}

In 556 of the cases (95\%), one or more ICFs were found. The total number was 772 , so there was an average of 1.4 ICFs per case when present. No specific individual factor could be identified in 29 cases (5\%). The most common ICF was "Negligence, forgetfulness or lack of attentiveness" in $68 \%$ of the cases. "Proper protocol not followed" occurred in $25 \%$ and "Lack of knowledge" in $13 \%$ of the cases. "Practice beyond scope" occurred in $12 \%$ of the cases and correlated strongly and positively with "unauthorized drug" ( $k=0.65, p<0.001)$ and negatively with "Negligence, forgetfulness or lack of attentiveness" $(k=-0.22, p<0.001)$. "Inappropriate communication" occurred in $11 \%$ of the cases and correlated positively with "Omission" $(k=0.25, p<0.001)$. Table 3 shows the frequency of the different ICFs along with stories illustrating the categories.

\section{The system contributory factors (SCFs)}

In 455 of the cases (78\%), one or more SCFs were found. The total number was 757 so when present, there was an average of 1.7 SCF per case. No SCF could be identified in 130 cases $(22 \%)$. The most common SCF was "Role overload" (36 \%) followed by "Unclear communication or orders" (30\%) and "Lack of adequate access to guidelines or unclear organisational routines" (30\%). "Inappropriate location of medication or look-alike medication" occurred in $14 \%$ and correlated strongly and positively with "Wrong drug" $(k=0.52, p<0.001)$. "Interruption or distraction when preparing or administering medication" occurred in $8 \%$ of the cases. Table 4 shows the frequency of the eight SCFs along with illustrating examples.

\section{Experienced versus un-experienced nurses}

Nurses with less than 2 years work experience were significantly more likely to make the error "Wrong patient due to mix-up of patients" $(p<0.007)$ and the error "Wrong route". $(p<0.003)$ than their more experienced colleagues. The un-experienced nurses were also more prone to the ICFs "Lack of knowledge" $(p<0.001)$ and "Negligence, forgetfulness or lack of attentiveness" 
Table 3 The six different categories of individual contributory factors

\begin{tabular}{|c|c|c|}
\hline $\begin{array}{l}\text { Individual } \\
\text { contributory factors }\end{array}$ & $N(\%)$ & Stories illustrating the categories. \\
\hline $\begin{array}{l}\text { Negligence, } \\
\text { forgetfulness or lack } \\
\text { of attentiveness }\end{array}$ & $399(68)$ & $\begin{array}{l}\text { One nurse put two vials on the table in } \\
\text { a cancer patient's home. The prescription } \\
\text { was Hydromorphone } 10 \mathrm{mg} / \mathrm{ml}, 1.8 \mathrm{ml} \\
\text { s.c. and Morphine } 10 \mathrm{mg} / \mathrm{ml}, 9 \mathrm{ml} \text { i.v. } \\
\text { Hydromorphone is five times stronger } \\
\text { than Morphine. } \\
\text { Another nurse gave an intravenous } \\
\text { injection from a } 10 \mathrm{ml} \text {. vial. When } \\
\text { she was about to give Hydromorphone, } \\
\text { that she believed existed only in } 1 \mathrm{ml} \\
\text { vials, she could not find it on the table. } \\
\text { She now realized that she has given } \\
\text { Hydromorphone instead of Morphine. } \\
\text { A temporarily employed doctor had } \\
\text { prescribed ordered both Morphine } \\
\text { and Hydromorphone in } 10 \mathrm{ml} \text { vials. }\end{array}$ \\
\hline
\end{tabular}

Proper protocol not followed

Practice beyond

scope of practice communication
147 (25) A man with acute stroke had recently been treated for a myocardial infarction and was therefore admitted to the cardiology department for treatment of his stroke. He was prescribed ateplase as thrombolytic therapy. The nurse was familiar with this drug in cardiology practice but not for stroke.

Alteplase consists of two vials to be mixed by the nurse, but the dosage and the preparation are different for different diagnoses. With one of the vials in her hand, the nurse walked around and asked several doctors and nurses about the procedure. Then she mixed the ateplase infusion and administered it to the patient. The next morning, the vial with the active ingredient was found at the table in the doctor's office.

76 (13) The same case as Proper protocol not followed.

68 (12) A nursing home patient with severe cancer pain was prescribed dextropropoxyphene and paracetamol 4 times a day and morphine $5 \mathrm{mg}$ "when needed". On a Saturday, pain had worsened in spite of morphine 4 doses daily. The $R N$ changes the order to paracetamol and morphine $5 \mathrm{mg}$ four times daily and excluded dextropropoxphene. The physician thought that the RN had passed her authorization when not consulting a physician.

62 (11) A nursing home patient was prescribed tramadol 1-2 tablets "when needed". The RN put 8 tablets in a medicine cup labelled "tramadol when needed". An assistant nurse with an authorization to administer drugs gave the patient all 8 tablets at the same time. The RN had failed in her communication to the
Table 3 The six different categories of individual contributory factors (Continued)

$\begin{aligned} & \text { assistant nurse giving } \\ & \text { incomplete information. }\end{aligned}$
$\begin{aligned} & \text { Disease } \\ & \text { or drug abuse }\end{aligned}$
$\begin{aligned} & \text { The nurse had used the patient's } \\ & \text { morphine herself. } \\ & \text { The patient did not get any morphine. } \\ & \text { identified }\end{aligned}$
$\begin{aligned} & \text { Total numbers of } \\ & \text { individual factors in } \\ & \text { the } 585 \text { cases }\end{aligned}$
$\begin{aligned} & \text { Table } 3 \text { shows the six different categories of individual contributory factors, } \\ & \text { the number and the percent calculated in relation to the } 585 \text { cases for each } \\ & \text { category and examples illustrating each category }\end{aligned}$

$(p<0.007)$ and the experienced nurses were more prone to "Practice beyond scope of practice" $(p<0.004)$ and to make MEs in spite of "Lack of adequate access to guidelines or unclear organisational routines" $(p<0.035)$. Table 5 shows the number and percent of the MEs, ICFs and the SCF split by nurse's work experience, and the $p$-values from Fisher's exact test.

\section{Patient outcome}

In 9 cases $(1.5 \%)$, the patients died as a result of the ME. In 29 cases (5\%), the patient was seriously harmed, in 64 cases (11\%) moderately harmed, and 466 (80\%) not harmed at all. Data was missing in 17 cases.

\section{Discussion}

The MEs and their contributing factors in this study of malpractice were mainly of the same types that were common in other studies around the world. We did not, however, find any cases of poor calculation skills, previously often blamed as an important cause of MEs [22, 23]. Today, nursing schools emphasize calculation skills and physicians must write exact orders. "Wrong dose" was overwhelmingly common (41\%) and was frequent in other studies like in US emergency departments (18\% out of 13,932 reported MEs) [10] and in the national reporting system of England and Wales (15.23\% out of 526186 reported errors) [24]. Those studies, however, include ME by others than RNs. Detailed comparisons of prevalence are inappropriate due to the heterogeneity of definitions, health care facilities, and reporting systems.

Some MEs like "Wrong patient" are always wrong, whereas others are relative. Three unquestionable types of MEs in our material were more common than in England and Wales 2005-2010: "Wrong route" occurred in $6 \%$ in our study but only in $1.51 \%$ in the England and Wales study: "Wrong drug" $16 \%$ compared to $9.28 \%$; "Wrong patient" $13 \%$ compared to $4.16 \%$ [24]. MEs of a type that is always wrong like "Wrong patient" are probably more likely to be reported and are more difficult 
Table 4 The eight different categories of system contributory factors

\begin{tabular}{lll}
\hline System factors & $N(\%)$ & \begin{tabular}{l} 
Stories illustrating the categories \\
\hline Role overload
\end{tabular} \\
$\begin{array}{l}\text { Inappropriate location of medication } \\
\text { or look-alike medication }\end{array}$ & $79(14)$ & $\begin{array}{l}\text { A child with a heart failure in an intensive care unit was to be } \\
\text { transported to another hospital. The nurse could not find sodium } \\
\text { chloride solution to flush the peripheral intravenous catheter and } \\
\text { went into another patient room where he found a tray of opened } \\
\text { sodium chloride solution vials. } \\
\text { He flushed the catheter and the child immediately turned blue } \\
\text { and stopped breathing. } \\
\text { Two unopened vials of sodium chloride and one opened vial of } \\
\text { potassium chloride were found on the tray. } \\
\text { The nurse had felt stressed. The child had been in a serious } \\
\text { condition during the night, and was not fed: The papers were } \\
\text { not ready and the transport car did not have access to oxygen. }\end{array}$ \\
&
\end{tabular}

An 80-year old lady was transferred from the intensive care unit to a general ward.

A nurse copied the patient's drug orders from the intensive care list to the medical care list by hand.

She wrote "Digoxin $0.25 \mathrm{mg} .1+1+1$ " instead of "Digoxin 1+0+0". The physician signed the order without noticing the error.

The patient got the higher dose during 12 days.

Lack of adequate access to guidelines or unclear organisational routines

"The case also illustrates "Proper protocol not followed" in Table III

Interruption or distraction when preparing or administering medication

Pressure from patient/patient's family or other staff members to satisfy the patient's immediate need

Administration in an emergency situation

None
A man with acute stroke had recently been treated for a myocardial infarction and was therefore admitted to the cardiology department for treatment of his stroke. He was prescribed alteplase as thrombolytic therapy. The nurse was familiar with this drug in cardiology practice but not for stroke.

Alteplase consists of two vials to be mixed by the nurse, but the dosage and the preparation are different for different diagnoses. With one of the vials in her hand, the nurse walked around and asked several doctors and nurses about the procedure. Then she mixed the ateplase infusion and administered it to the patient

The next morning, the vial with the active ingredient was found at the table in the doctor's office.

A nurse was preparing an infusion of furosemide and sodium chloride and in the room for storage and preparation of medications. The door was open and another patient in pain asked for morphine and begged the nurse to hurry up. The nurse replied that she would first finish what she started and then come with the morphine. The patient was standing in the door and talked to the nurse when she prepared the infusion.

She mixed morphine instead of furosemide in the infusion and gave to a patient with heart failure.

The nurse wrote that when she prepared the infusion, she was thinking of the patient needing morphine.

A patient would receive chemotherapy and the pharmacy delivered the wrong drug. The name of the mis-delivered vial was long and therefore an abbreviation was used. The difference in name between the various drugs did not appear in the abbreviation. The nurse read the abbreviation on the vial and compared with the prescription.

The nurse took for granted that it was the right drug delivered and gave it to the patient.

A father came with his 7 year old son to the health centre. He claimed that it was the day for his son to get his monthly injection of growth hormone.

The RN had worked in the centre for 2 weeks and could not find any notes about the injection in the child's medical record. She questioned if it was the right day and what dose to give. The father was stubborn and claimed that he knew the dose and that his son must have his injection.

The father seemed trustworthy and the RN gave the boy the injection. The boy got a too high dose and one week too early.

The patient got a double dose of furosemide due to a communication misunderstanding in an acute situation.

$130(22)$

Total numbers of system factors in the 585 cases

757

Table 4 shows the eight different categories of system contributory factors, the number and the percent calculated in relation to the 585 cases for each category and examples illustrating each category 
Table 5 The medication errors, the individual contributory factors and the system contributory factors in relation to the nurses' work experience

\begin{tabular}{|c|c|c|c|c|}
\hline & & \multicolumn{2}{|c|}{ Nurse's work experience } & \multirow{3}{*}{$p$} \\
\hline & & $0-2$ years & $>2$ years & \\
\hline & & $n=55$ & $N=317$ & \\
\hline \multicolumn{5}{|c|}{ Error type } \\
\hline 1 & Wrong dose & $20(36.4 \%)$ & $140(44.2 \%)$ & 0.305 \\
\hline 2 & $\begin{array}{l}\text { Wrong drug due to mix-up } \\
\text { of drugs }\end{array}$ & $9(16.4 \%)$ & $51(16.1 \%)$ & 1.000 \\
\hline 3 & $\begin{array}{l}\text { Wrong patient due to mix-up } \\
\text { of patients }\end{array}$ & $14(25.5 \%)$ & $34(10.7 \%)$ & 0.007 \\
\hline 4 & Omission & $3(5.5 \%)$ & $35(11.0 \%)$ & 0.332 \\
\hline 5 & Unauthorized drug & $2(3.6 \%)$ & 35 (11.0\%) & 0.139 \\
\hline 6 & Wrong route & 9 (16.4\%) & $14(4.4 \%)$ & 0.003 \\
\hline 7 & $\begin{array}{l}\text { Wrong judgement or inadequate } \\
\text { assessment of the patient's need } \\
\text { for treatment }\end{array}$ & $1(1.8 \%)$ & $9(2.8 \%)$ & 1.000 \\
\hline 8 & $\begin{array}{l}\text { Wrong management or storage } \\
\text { of the drug }\end{array}$ & $1(1.8 \%)$ & 7 (2.2\%) & 1.000 \\
\hline 9 & Allergy-related error & $0(0.0 \%)$ & $5(1.6 \%)$ & 1.000 \\
\hline \multicolumn{5}{|c|}{ Individual contributory factor } \\
\hline 1 & $\begin{array}{l}\text { Negligence, forgetfulness } \\
\text { or lack of attentiveness }\end{array}$ & $46(83.6 \%)$ & $207(65.3 \%)$ & 0.007 \\
\hline 2 & Proper protocol not followed & $13(23.6 \%)$ & $82(25.9 \%)$ & 0.867 \\
\hline 3 & Lack of knowledge & 17 (30.9 \%) & $37(11.7 \%)$ & 0.001 \\
\hline 4 & $\begin{array}{l}\text { Practice beyond scope } \\
\text { of practice }\end{array}$ & $1(1.8 \%)$ & $48(15.1 \%)$ & 0.004 \\
\hline 5 & Inappropiate communication & $3(5.5 \%)$ & $33(10.4 \%)$ & 0.328 \\
\hline 6 & Disease or drug abuse & $1(1.8 \%)$ & $13(4.1 \%)$ & 0.703 \\
\hline \multicolumn{5}{|c|}{ System contributory factor } \\
\hline 1 & Role overload & $25(45.5 \%)$ & 117 (36.9 \%) & 0.233 \\
\hline 2 & $\begin{array}{l}\text { Unclear communication } \\
\text { or orders }\end{array}$ & $13(23.6 \%)$ & 87 (27.4 \%) & 0.624 \\
\hline 3 & $\begin{array}{l}\text { Lack of adequate access } \\
\text { to guidelines or unclear } \\
\text { organisational routines }\end{array}$ & 9 (16.4 \%) & 97 (30.6 \%) & 0.035 \\
\hline 4 & $\begin{array}{l}\text { Inappropriate location } \\
\text { of medication or look-alike } \\
\text { medication }\end{array}$ & 7 (12.7 \%) & 40 (12.6\%) & 1.000 \\
\hline 5 & $\begin{array}{l}\text { Interruption or distraction } \\
\text { when preparing or } \\
\text { administering medication }\end{array}$ & 8 (14.5 \%) & 22 (6.9 \%) & 0.064 \\
\hline 6 & $\begin{array}{l}\text { Inadequate technique or } \\
\text { pharmaceutical service }\end{array}$ & $2(3.6 \%)$ & $23(7.3 \%)$ & 0.557 \\
\hline 7 & $\begin{array}{l}\text { Pressure from patient/family } \\
\text { or other staff members to } \\
\text { satisfy the patient's } \\
\text { immediate needs }\end{array}$ & 2 (3.6 \%) & $21(6.6 \%)$ & 0.551 \\
\hline 8 & $\begin{array}{l}\text { Administration in an } \\
\text { emergency situation }\end{array}$ & $1(1.8 \%)$ & $6(1.9 \%)$ & 1.000 \\
\hline
\end{tabular}

Table 5 shows the number of medication errors, individual contributory factors and system contributory factors ( $n$ and \%) split by the nurses' work experience: $0-2$ years or $>2$ years. and $p$-values from Fisher's exact test. Bold data show the statistically significant correlations to conceal. When a lot of consideration is needed to assess whether an ME is present or not, it is less likely to be reported. If a nurse does not give insulin to a patient who had not eaten much, it may be classified as "Omission" or as good judgement depending on what measures are taken to check the patient's condition and needs. Inexperienced nurses were much more likely to make the ME "Wrong route" and "Wrong patient". Since every senior health care professional personally has experienced mix-up of patients, they have learnt to always double-check patient identity. Experience is also helpful to understand the variety of medication routes.

In $95 \%$ of the cases, one or more ICF were present and in $78 \%$ one or more SCF showing the complexity of MEs. The most common ICF "Negligence, forgetfulness or lack of attentiveness" occurred in two thirds of the cases. The most frequent SCFs were "Role overload", "Unclear communication or orders" and "Lack of adequate access to guidelines or unclear organisational routines". Although distractions and interruptions are frequently blamed for errors in other studies $[25,26]$ the SCF "Interruption or distraction when preparing or administering medication" occurred only in $8 \%$ of the cases in the present study. Our figure is similar to $7.5 \%$ in US emergency departments [10], but in a psychiatric setting, distraction was cited as the most common contributory factor (15.2 \%) [27]. We did not find that clinically inexperineced nurses were more affected by system factors than experienced nurses. "Wrong drug" correlated strongly with the SCF "Inappropriate location of medication or look-alike medication". This is a system factor that easily can be improved.

Two thirds of the patients in this study were older than 65 or younger than 18 years of age. Most pharmaceutical studies exclude the youngest, the oldest and the most vulnerable patients. In the 21st century, it is necessary to make pharmaceutical studies designed for those in the greatest need of advanced care. Other types of clinical studies must be developed and carried out in those that do not fit into simple double-blind studies. The patients must also be given appropriate attention in every-day care settings.

Due to the complexity of the causes behind MEs and the large differences between work-places, no single action will solve the problems involved and each workplace must work with the safety issues. Work-place routines must pay regards to human weaknesses. Policies and procedures should be easily available, updated, well known and easy to read. The rooms for storage and preparation of medication must be well structured and nurses left undistracted during the medication process. The individual nurse should be trained to make priority to safety rather than being by tradition available to everyone all the time. Nurse leaders must ensure that newly graduated nurses as well as experienced nurses have the necessary skills for their tasks. Workload and the complexity of the tasks must be individualized 
based on the nurse's experience and knowledge. Continuous education is crucial for safety in the rapidly changing world of care. An organizational culture that encourages recognition and learning from errors rather than blaming and shaming promotes safety.

Although this was a study analyzing hazardous MEs, $80 \%$ of the patients were not harmed at all. This shows that there is vigilance and attention when errors have occurred in the health care system. An important gate-keeper for MEs is the alert and well informed patient, but the situation is more complicated for the critically ill, very young or very old patient who has to rely on the professional work of the staff. A suggestion for further research is a study of factors that hold back serious consequences of MEs.

\section{Conclusions}

To err is human, and the MEs regarded as malpractice in Sweden were of the same character as MEs worldwide. A complex interplay between individual and system factors often contributed to the errors. Workplaces must work systematically with patient safety routines, and care for the well-being and the continuous education of the employees.

\section{Acknowledgements}

We are grateful to the NBHW for selecting the cases for the study.

\section{Funding}

This study was supported by a generous grant from Stiftelsen Olle Engkvist Byggmästare.

\section{Availability of data and materials}

The data-sets generated during the current study are not publicly available in order to preserve the privacy of patients, nurses and health care providers, but are available from the corresponding author upon reasonable request.

\section{Authors' contributions}

$J U, M B$ and EAK conceived of the study, made the study design. JU and MB made the data collection. LB carried out all calculations. All authors participated in data analysis. KSB and MB drafted the manuscript. All authors read and approved of the final manuscript.

\section{Competing interests}

The authors declare that they have no competing interests.

\section{Consent for publication}

Not applicable.

\section{Ethics approval and consent to participate}

This study was approved by the Regional Ethical Review Board, Stockholm, Sweden (2009/1416-32). Patients, nurses, healthcare providers and organizations have not been asked for approval to participate. The Regional Ethical Review Board has waived the need for formal approval of the participants. All information that can identify them has been carefully removed.

\section{Author details}

'Department of Neurobiology, Care Sciences and Society, Karolinska Institutet, Stockholm, Sweden. ${ }^{2}$ Department of Clinical Science and Education Södersjukhuset, Karolinska Institutet, Stockholm, Sweden. ${ }^{3}$ Department of Internal Medicine, Södersjukhuset AB, SE-118 83 Stockholm, Sweden. ${ }^{4}$ Psychiatry South Stockhholm, Administration och Ledning, Box 5040SE-121 05 Johanneshov, Sweden.

\section{References}

1. Holmstrom AR, Laaksonen R, Airaksinen M. How to make medication error reporting systems work-Factors associated with their successful development and implementation. Health Policy. 2015.

2. WHO. Reporting and learning systems for medication errors: the role of pharmacovigilance centres. In. Edited by WHO; 2014. http://www.who.int/ medicines/areas/quality_safety/safety_efficacy/emp_mes/en/.

3. Joolaee S, Hajibabaee F, Peyrovi H, Haghani H, Bahrani N. The relationship between incidence and report of medication errors and working conditions. Int Nurs Rev. 2011;58(1):37-44.

4. Cohen H, Robinson ES, Mandrack M. Getting to the root of medication errors: Survey results. Nursing. 2003;33(9):36-45.

5. Bergqvist M, Karlsson EA, Björkstén KS, Ulfvarson J. Medication Errors by Nurses in Sweden-Classification and Contributing factors. Open Access Scientific Reports. 2012;1(11):1-5.

6. McLeod MC, Barber N, Franklin BD. Methodological variations and their effects on reported medication administration error rates. BMJ Qual Saf. 2013;22(4):278-89.

7. Brady AM, Malone AM, Fleming S. A literature review of the individual and systems factors that contribute to medication errors in nursing practice. J Nurs Manag. 2009;17(6):679-97.

8. Chang YK, Mark BA. Antecedents of severe and nonsevere medication errors. J Nurs Scholarsh. 2009:41(1):70-8.

9. Reason J. Understanding adverse events: human factors. Qual Health Care. 1995:4(2):80-9.

10. Pham JC, Story JL, Hicks RW, Shore AD, Morlock LL, Cheung DS, Kelen GD, Pronovost PJ. National study on the frequency, types, causes, and consequences of voluntarily reported emergency department medication errors. J Emerg Med. 2011;40(5):485-92.

11. Armitage $\mathrm{G}$, Knapman $\mathrm{H}$. Adverse events in drug administration: a literature review. J Nurs Manag. 2003;11(2):130-40.

12. McBride-Henry K, Foureur M. Medication administration errors: understanding the issues. Aust J Adv Nurs. 2006;23(3):33-41.

13. Davis L, Ware R, McCann D, Keogh S, Watson K. Evaluation of contextual influences on the medication administration practice of paediatric nurses. J Adv Nurs. 2009:65(6):1293-9.

14. Fasolino T, Snyder R. Linking nurse characteristics, team member effectiveness, practice environment, and medication error incidence. J Nurs Care Qual. 2012;27(2):E9-16.

15. Prot $\mathrm{S}$, Fontan JE, Alberti C, Bourdon O, Farnoux C, Macher MA, Foureau A, Faye A, Beaufils F, Gottot $S$, et al. Drug administration errors and their determinants in pediatric in-patients. International J Qual Health Care. 2005;17(5):381-9.

16. Seki Y, Yamazaki Y. Effects of working conditions on intravenous medication errors in a Japanese hospital. J Nurs Manag. 2006;14(2):128-39.

17. Tang FI, Sheu SJ, Yu S, Wei IL, Chen $\mathrm{CH}$. Nurses relate the contributing factors involved in medication errors. J Clin Nurs. 2007;16(3):447-57.

18. Westbrook Jl, Rob Ml, Woods A, Parry D. Errors in the administration of intravenous medications in hospital and the role of correct procedures and nurse experience. BMJ Qual Saf. 2011;20(12):1027-34.

19. Mayo AM, Duncan D. Nurse perceptions of medication errors: what we need to know for patient safety. J Nurs Care Qual. 2004;19(3):209-17.

20. Wilkins K, Shields M. Correlates of medication error in hospitals. Health Rep. 2008:19(2):7-18.

21. Graneheim UH, Lundman B. Qualitative content analysis in nursing research: concepts, procedures and measures to achieve trustworthiness. Nurse Educ Today. 2004;24(2):105-12.

22. Carlton G, Blegen MA. Medication-related errors: a literature review of incidence and antecedents. Annu Rev Nurs Res. 2006:24:19-38.

23. Wright K. Do calculation errors by nurses cause medication errors in clinical practice? A literature review. Nurse Educ Today. 2010;30(1):85-97.

24. Cousins DH, Gerrett D, Warner B. A review of medication incidents reported to the National Reporting and Learning System in England and Wales over 6 years (2005-2010). Br J Clin Pharmacol. 2012;74(4):597-604.

25. Mrayyan MT, Shishani K, Al-Faouri I. Rate, causes and reporting of medication errors in Jordan: nurses' perspectives. J Nurs Manag. 2007;15(6):659-70.

26. Hicks RW, Becker SC, Windle PE, Krenzischek DA. Medication errors in the PACU. J Perianesth Nurs. 2007;22(6):413-9.

27. Haw C, Cahill C. A computerized system for reporting medication events in psychiatry: the first 2 years of operation. J Psychiatr Ment Health Nurs. 2011; 18(4):308-15. 